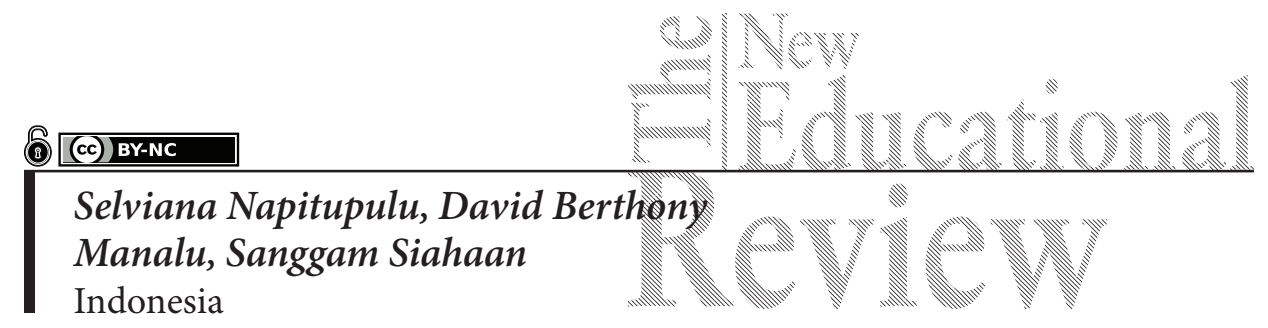

\title{
Scientific Approach-Based English Learning Strategy (SABELS)
}

DOI: 10.15804/tner.2019.56.2.03

\begin{abstract}
The Indonesian government has decided to apply a scientific approach to all academic subjects. This decision brings serious consideration since it is new especially in language learning. Some researchers claim that the implementation of this new approach is not optimal because language teachers have never been introduced to a scientific approach. Grounded theory research was conducted to solve this situation. A new strategy has been formulated and called a scientific approach-based English learning strategy (SABELS), where students' curiousity and willingness to communicate in English are the primary aspects teachers should establish before initiating the teaching and learning process. The learning process in this strategy includes: observing, questioning, collecting information, associating, and communicating. While establishing context, enlightening, monitoring, assisting, and evaluating are focused on the teacher's activities. In conclusion, applying this new strategy will encourage both teacher and students to be more creative and innovative.
\end{abstract}

Keywords: curiosity, scientific approach-based English learning strategy, willingness

\section{Introduction}

\section{I.1. Background}

The 2013 curriculum introduces a new atmosphere in Indonesian education. Education is expected to produce the nation's next generation, who has not only 
knowledge, but also character and skills. One of the striking changes in the 2013 curriculum is the application of a scientific approach to the entire learning process. Through a scientific approach, students are expected to be able to think critically and in a skillful way.

The steps of the scientific approach in the learning process according to the Regulation of the Minister of Education and Culture of Indonesia, Number 81A 2013 attachment IV, are observing, questioning, collecting information, associating, and communicating. For certain subjects, materials, or situations, it is very likely that these steps are not always appropriately applied. In conditions like this, the learning process must still apply scientific values or traits and avoid non-scientific ones.

As an integral part of the 2013 curriculum, the scientific approach is certainly familiar to teachers in schools. However, in reality, the scientific approach is still controversial, especially in English learning. Several studies have been carried out to explore the application of this scientific approach in English learning, such as Budianto (2014), Wahyudin \& Sukyadi (2015), Azizah (2015), and Zaim (2017). The relevance of their findings shows that the concepts and strategies for applying the scientific approach are still unclear to many English teachers.

Methods or approaches in language learning have different concepts and techniques with a scientific approach. Some methods or approaches that have been applied in learning English are as mentioned by Larsen-Freeman (2000), Richards and Rodgers (2001), and Brown (2007), namely: Grammar-Translation Method, Direct Method, Audio-Lingual Method, Silent Way, Desuggestopedia, Total Physical Response, Community Language Learning, Communicative Language Teaching, Natural Approach, Cooperative Language Learning, and Task-Based Language Teaching. Thus, that scientific learning model is confusing for language teachers.

\section{I.2. Research Problem}

Through questionnaire and observation in some senior high schools in Pematangsiantar City, it was found that some teachers were able to explain activities in each step of the scientific approach separately, but the concept of scientific approach as a whole is not yet understood. The learning process they formulated was not related to activities in one step to next steps. Based on the results of observations through video recordings, the learning model applied by the teacher is not a scientific approach but conventional learning, where the teacher takes the majority of the learning time allocation to explain material. Students are merely listeners. This phenomenon was a starting point to conduct this grounded theory research. The result is expected to help language teachers, especially English teachers, to apply the scientific approach to teaching English. 


\section{Methodology}

\section{II.1. Research Design}

This research is a type of grounded theory. Glaser \& Strauss (1967) stated that grounded theory is a qualitative research methodology that emphasizes theoretical discovery from empirical observation data in the field by inductive methods (finding theory of a number of data), generative discovery or construction of theory using data as evidence, constructive finding theory construction or categories through analysis and abstracting, and subjective processes, namely reconstructing the interpretation and meaning of research results based on the conceptualization of the research subject.

\section{II.2. Data Collection}

In grounded theory, everything that the researcher encounters when studying a certain area is data - not only interviews or observations but anything that helps the researcher to generate concepts for emerging theory. The data were collected in June 2018, by using non participatory observation. The researchers observed five videos of the newest teaching model in the Indonesian curriculum released by the Ministry of Education and Culture of Indonesia.

\section{II.3. Data Analysis Procedure}

There are three stages of data analysis in Grounded Theory (Strauss and Corbin, 1990):

a) Open coding. This involves line by line coding, where concepts and key phrases are identified and highlighted and moved into sub-categories, then categories. This breaks down data into conceptual components and the researcher can start to theorise or reflect on what they read and understand making sense of the data. The data from each participant will be constantly compared to find similarities.

b) Axial coding. At this stage, relationships are identified between categories, and connections are identified.

c) Selective coding. This involves identifying the core category and methodically relating it to other categories. Relationships must be authenticated and categories refined. Categories are then integrated together and a grounded theory identified. Analytical notes are encouraged. These are notes to oneself to explain thought patterns in relation to data analysis. Final theory is usually generated from the integration of several analytical memos. 
The researchers began by coding the duration of each teaching video. Similar codes were then grouped to form sub-categories and within these sub-categories, categories were identified. The researchers then grouped the categories to form theory related to the application of the scientific approach. The process of data collection continued until each category was saturated and no new data emerged.

\section{Results}

\section{III.1 Design of Scientific Approach-Based English Learning Strategy (SABELS)}

To achieve successful learning by using SABELS, the roles of the teacher and students in the teaching and learning process should be determined clearly. First, the teacher should be able to establish the learning context. This may refer to the use of audio-visual media. By showing videos, it is expected that the basic knowledge of the students will be activated. After that, the teacher gives explanation related to learning material and also assigns students to group work. While the students are in group work, the teacher is supposed to monitor the learning process. Beside that, the teacher is also expected to assist students' group work in solving some problems they face during discussion. The last role of the teacher is evaluating the discussion results.
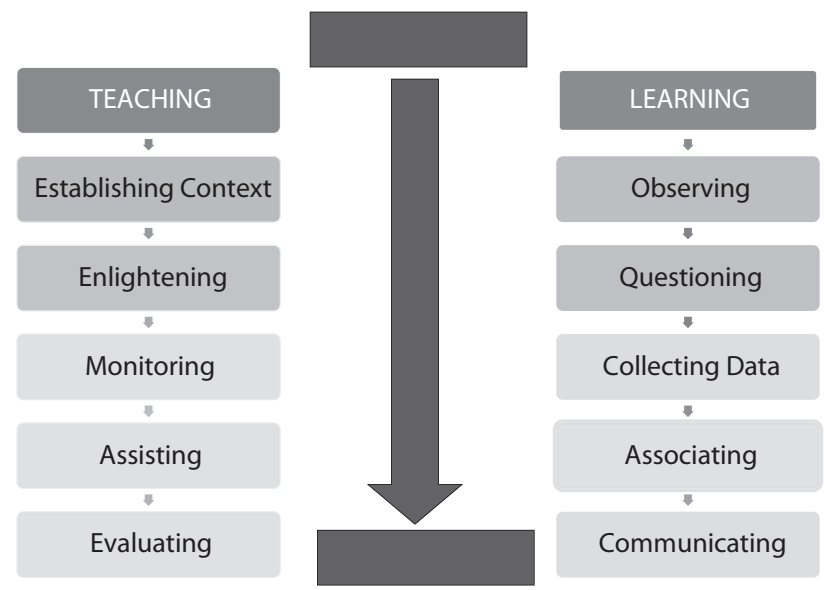

Figure 1. SABELS Process 
Students, as the main actors of the learning process, should be encouraged to do 5 steps of learning. The first step is observing, where students will watch videos of learning material. Guided questions should also be provided in this step, in order to maintain the objective of using the media. In the next step, students will have a chance to pose some questions related to what they have just watched from the media. At the beginning, it may seem difficult for students to pose questions. In this case, the teacher may help them by showing some examples of questions related to the material. Students should be trained well in these steps since it will raise their curiosity to learn the topic. After that, they work in group to collect information related to some tasks assigned. The use of the internet is really needed in this step. This makes the teacher allow and monitor the use of some gadgets. It is believed that the use of gadgets in the learning process will bring excitement to students so that learning will be more interesting. Next is associating. This step refers to the process of understanding and analyzing information, and also designing the report of discussion. It may take a lot of time to accomplish this step. That is why the teacher should not limit the use of SABELS only to one meeting since the nature of the scientific process cannot be achieved instantly. The last step is students' report of their discussion results in the form of presentation. This will encourage students to be more responsible for what they have just learnt. While presenting results, various responses and arguments may come from other students. Here, the teacher is required to mediate the issues arising. Students should be free to express their arguments as long as they are relevant to the topic. This action will teach students to be critical.

\section{III.2. Steps to Implement SABELS}

Below is the design of steps to implement SABELS, which clearly displays the integration of three competences (i.e., linguistic knowledge, character building, and language skills) students should have at the end of learning.

\section{Discussion}

In line with the basic concept of scientific approach, the SABEL strategy encourages students to learn English by curiosity. The learning steps are observing, questioning, collecting, associating, and communicating. The process of learning English is primarily motivated by their willingness to speak and write in English. This means the teacher should be the one who can develop their creativity and innovation. 


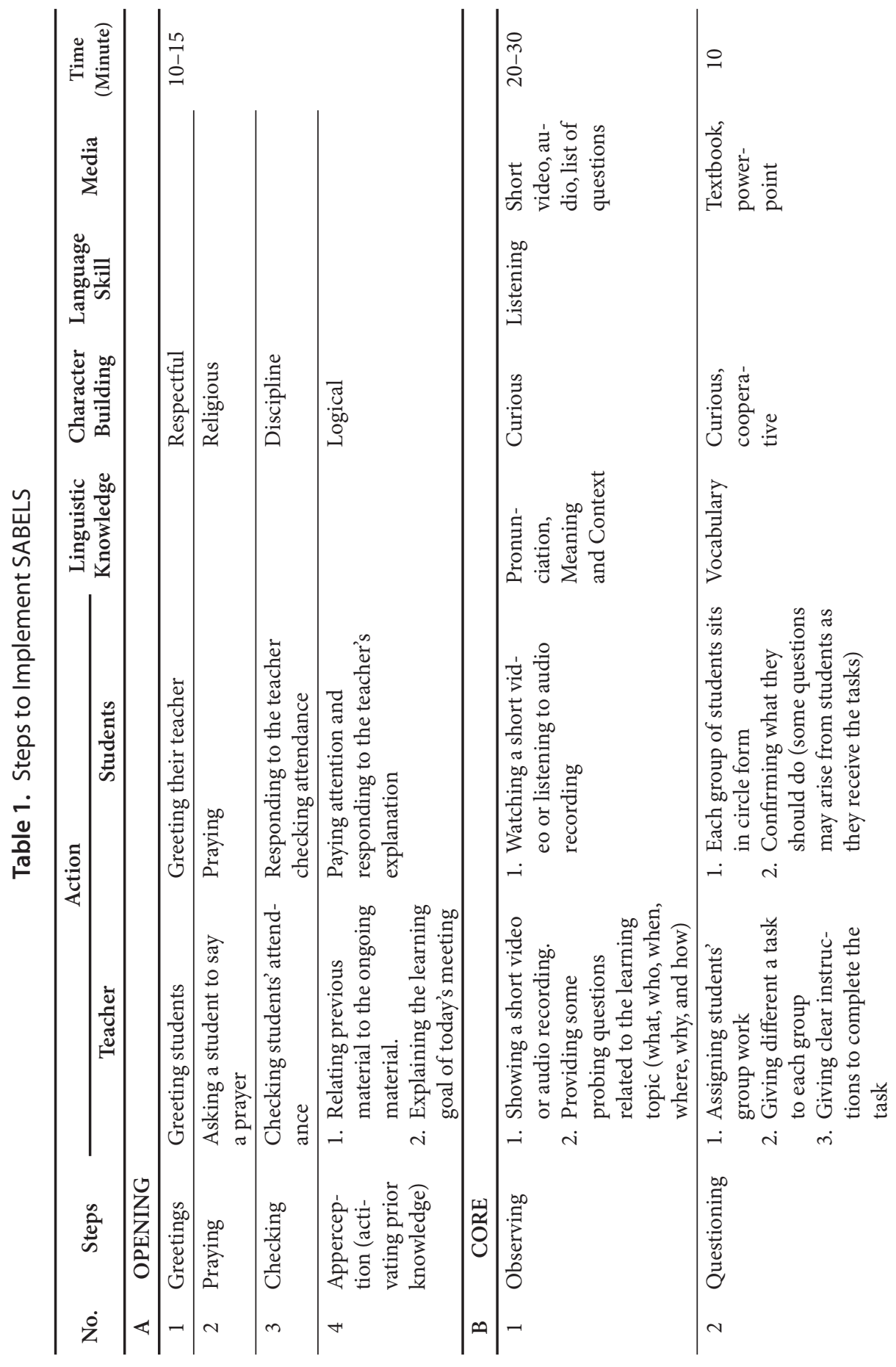




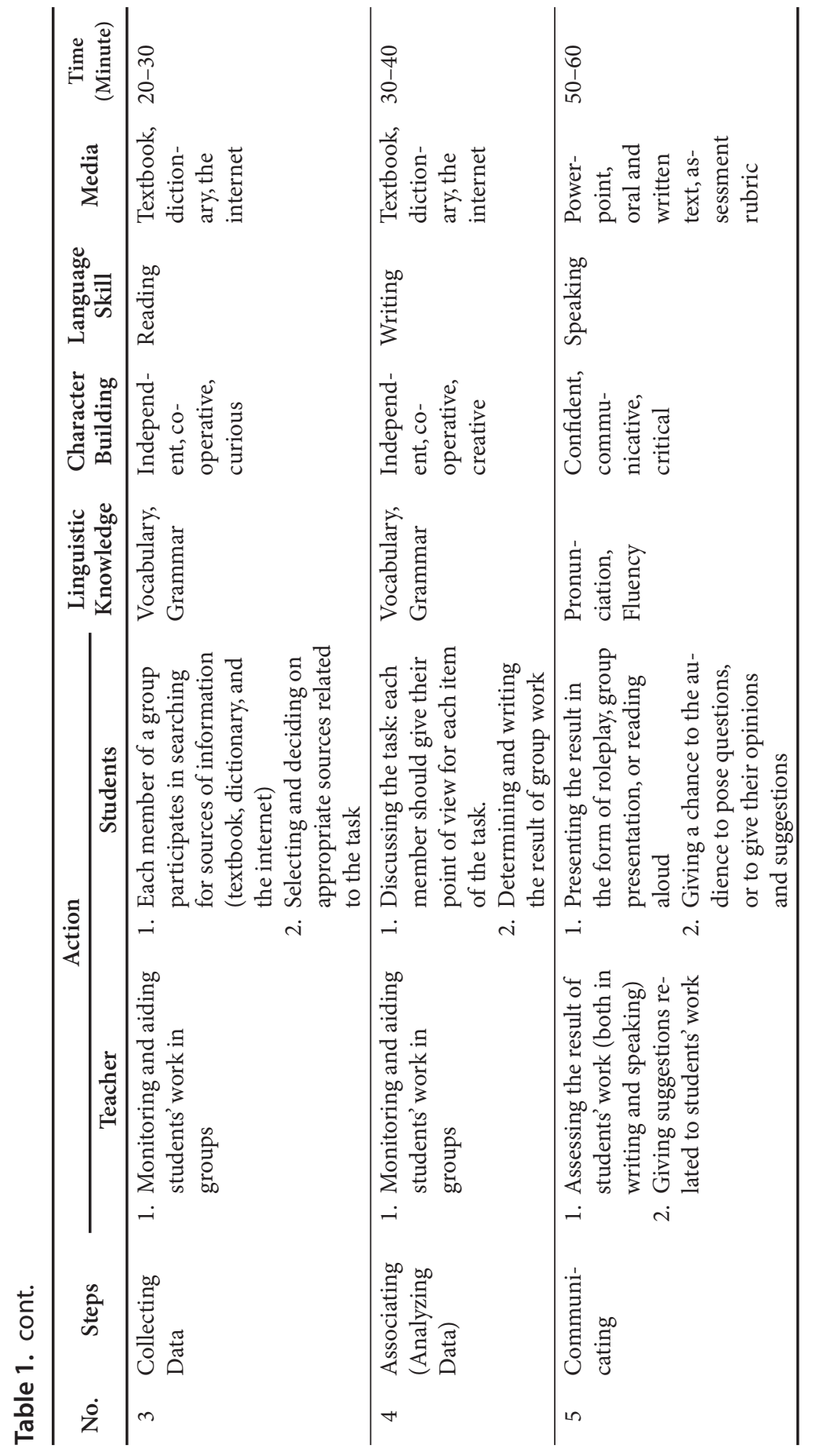




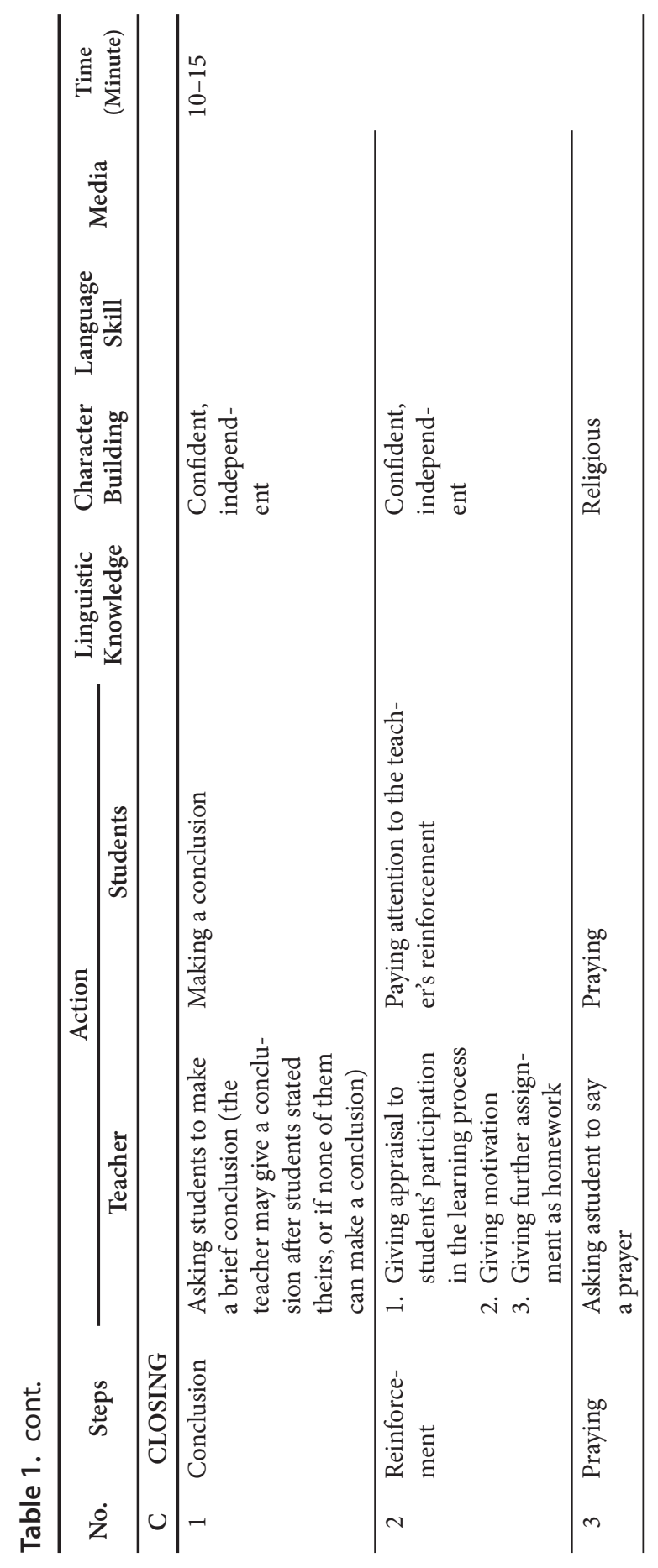


There are four points to be considered and prepared by English teachers in applying this strategy. Firstly, audio-visual media is strongly needed to establish the context of the material being learnt. This media is primarily used in the first step of the learning process, i.e., observing. The teacher is required to be able to select approprite and relevant videos to the learning goal and material. Secondly, there should not be any prohibition to use gadgets. The use of the internet will be very helpful for students to collect any information related to the learning topic. In this case, the teacher should be careful in monitoring students' work with their gadgets. The teacher may lead them to access certain sites which are relevant to their tasks. Nevertheless, it will be much wiser if the school provides secured or trusted network so that inappropriate contents cannot be accessed by students. Thirdly, the integration of knowledge, skills, and character is necessary to encourage students to be productive, creative, innovative, and affective. Knowledge refers to linguistic competence such as phonology, morphology, syntax, semantics, pragmatics, and discourse. Skill involves receptive skills (listening and reading) and productive skills (speaking and writing). Character is a positive attitude to communication.

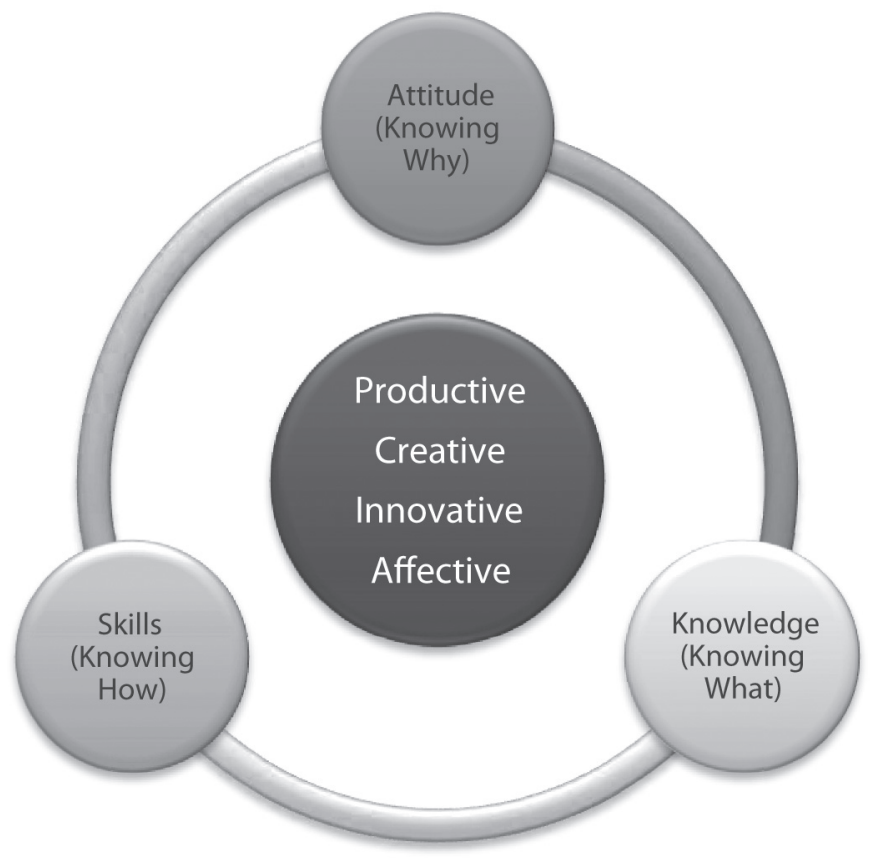

Figure 2. The Integration of knowledge, skills and attitude in SABELS 


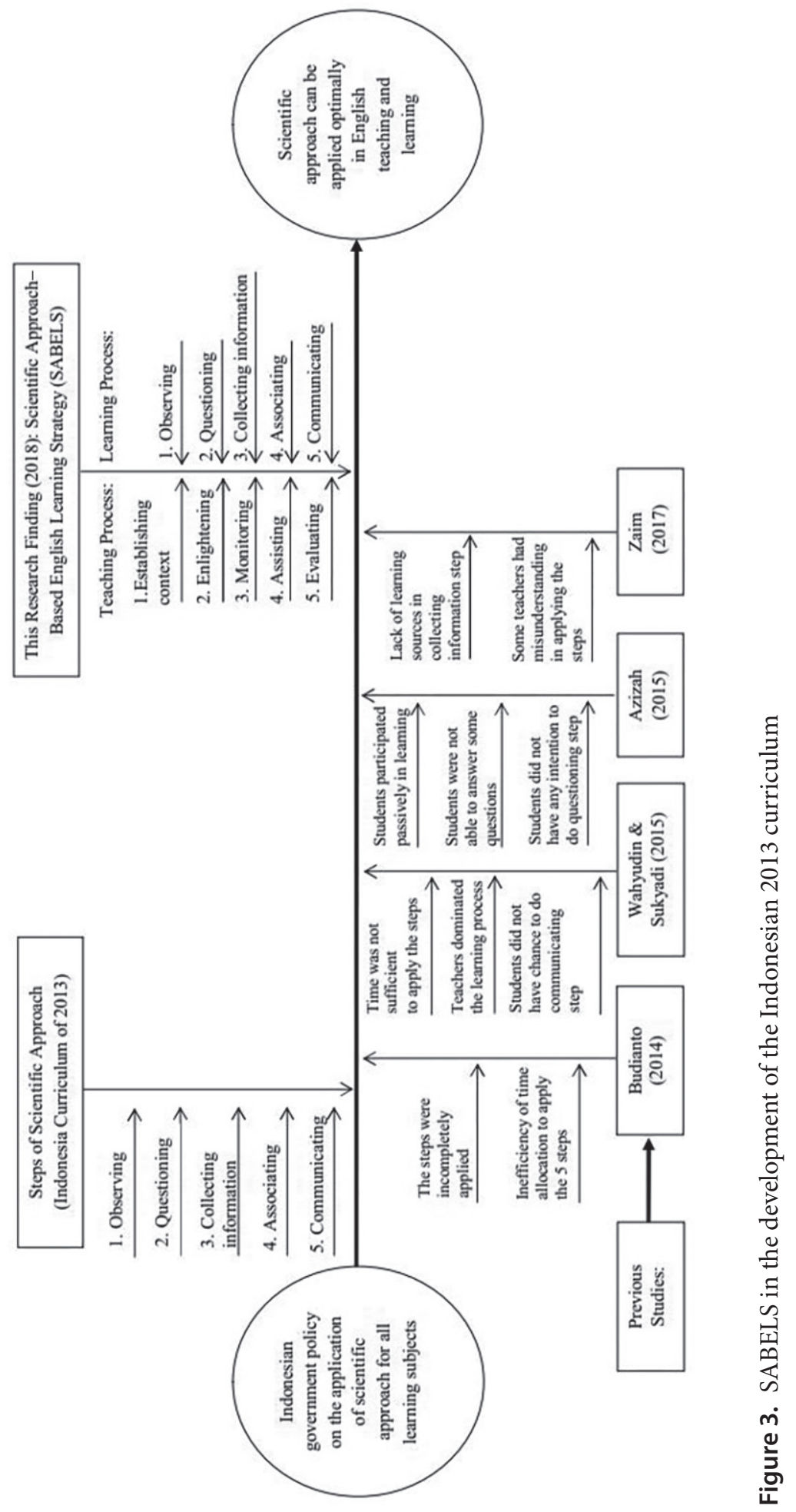


Lastly, the distribution of each learning step (observing, questioning, collecting, associating, and communicating) is not limited to one meeting. The teacher may continue the learning steps in the next meetings. It depends on the level of the difficulty of the material.

\section{Role of SABELS in the development of the Indonesian 2013 curriculum}

Since the emergence of the Indonesian 2013 curriculum followed by the establishment of some government laws, the application of scientific approach has been problematic in English teaching and learning. It is mostly because English teachers do not know how to implement that approach. Many studies have been conducted to identify things hindering the application of the scientific approach. Nevertheless, none of them has tried to find solutions. The presence of SABELS will help teachers since this strategy includes detailed information not only about what students do but also what the teacher should do in the classroom.

\section{Conclusion}

Planning scientific language learning activities is not easy and may be confusing for language teachers. This may occur if teachers misunderstand the concept of scientific approach. SABELS is designed to help language teachers to integrate the scientific approach in language learning. Application of SABELS focuses not only on the knowledge domain (i.e., linguistic aspects), but also on increasing language skills and enhancing character building. This will lead both teachers and students to be creative and innovative in the teaching and learning process.

\section{References}

Azizah, S. (2015). Implementasi pendekatan scientific dalam pengajaran Bahasa Inggris Kurikulum 2013 di SMPN 1 Pamekasan (The implementation of the scientific approach in teaching English based on the 2013 curriculum at State Junior High School 1 Pamekasan). OKARA Jurnal Bahasa dan Sastra, 2, 181-200. https://doi.org/10.19105/ojbs. v9i2.688.

Brown, H.D. (2007). Principles of language learning and teaching. $5^{\text {th }}$ ed. New York: Pearson Education.

Budianto, D.E. (2014). Teacher's pedagogical competence in the implementation of 2013 English Curriculum (Abstract). Paper presented in International Postgraduate Colloquium of Research in Education (IPCORE). Bandung. 
Corbin, J., \& Strauss, A. (1990). Grounded theory research: Procedures, canons, and evaluative criteria. Qualitative Sociology, 13(1), 3-21. https://doi.org/10.1007/BF00988593

Glaser, B.G., \& Strauss, A.L. (1967). The discovery of grounded theory: Strategies for qualitative research. Chicago: Aldine.

Larsen-Freeman, D. (2000). Techniques and principles in language teaching. $2^{\text {nd }}$ ed. Oxford: Oxford University Press.

Curriculum Implementation. Regulation of Minister of Education and Culture of Indonesia. No. 81A attachment IV (2013).

Richards, J.C., \& Rodgers, T.S. (2001). Approaches and methods in language teaching. $2^{\text {nd }}$ ed. Cambridge: Cambridge University Press.

Wahyudin, A.Y. \&D. Sukyadi (2015). A closer look at the implementation of the curriculum 2013 in Indonesia: Should the scientific approach be used in EFL classroom? Rangsit Journal of Educational Studies, 2(2), 56-70. https://doi.org/10.14456/rjes.2015.11.

Zaim, M. (2017). Implementing scientific approach to teach English at senior high school in Indonesia. Asian Social Science, 13(2), 33-40. https://doi.org/10.5539/ass.v13n2p33. 